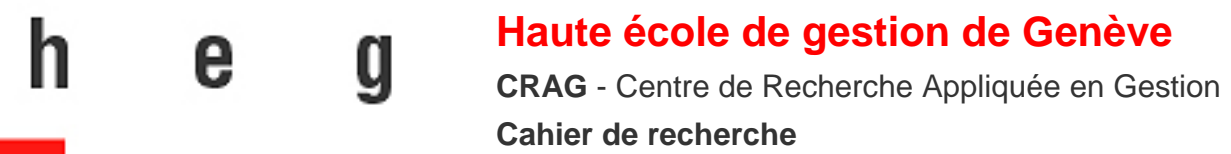

\title{
Paying enough taxes already? Testing the acceptability of carbon taxes with survey data
}

Stefano Carattini \& Andrea Baranzini

$N^{\circ}$ HES-SO/HEG-GE/C--14/2/1--CH

2014 


\title{
Paying enough taxes already? Testing the acceptability of carbon taxes with survey data
}

\author{
Stefano Carattini \\ Andrea Baranzini
}

Working paper

Juillet 2014

\begin{abstract}
In spite of economist's claims, climate policy instruments such as carbon taxes are rarely implemented. This paper analyzes the drivers of carbon taxes acceptability in the semi-direct democratic context of Geneva, Switzerland. Based on a sample of more than 300 individuals, we assess the effect on acceptability of socioeconomic characteristics, environmental attitudes, social norms as well as individual's perceptions of carbon taxes advantages and disadvantages. We also show that policy design matters for acceptability, in particular earmarking for environmental purposes, and find evidence of an effect of labeling, "climate contribution" leading under some circumstances to larger acceptability than "carbon tax". We infer that proper policy design coupled with effective communication on the effects of carbon taxes may lead to a substantial improvement in acceptability.
\end{abstract}

\section{Keywords}

Climate policy; Carbon tax; $\mathrm{CO}_{2}$ emissions; Switzerland

\section{JEL Classification}

D72 - H23 - Q48 - Q52 - Q58 


\title{
Paying enough taxes already? Testing the acceptability of carbon taxes with survey data
}

\author{
Stefano Carattini ${ }^{*, \dagger} \ddagger$ and Andrea Baranzini ${ }^{\dagger}$
}

July 2014

\section{Introduction}

International negotiations have aimed to stabilize greenhouse gases concentrations at levels that would prevent dangerous interferences with the climate system. However, there is increasingly evidence showing that current mitigation efforts are by large not enough (UNEP 2013). This result comes as no surprise. Despite economists assessed their theoretical cost-effectiveness long time ago (cf. e.g. Baumol and Oates 1971), powerful policy instruments to reduce greenhouse gas emissions such as carbon taxes are rather barely implemented (Baranzini and Carattini 2013). A growing strand of literature addresses the political economy of carbon taxes by looking at the power of lobbying (cf. e.g. Godal and Holtsmark 2001; Felder and Schleiniger 2002; Kirchgassner and Schneider 2003; Sterner 2007; Spash and Lo 2012). Instead, public acceptability is less explored. Finding publicly acceptable solutions for decarbonizing our economy is however a clear priority (Metcalf 2009). With this aim, we conduct a survey on over 300 individuals from the Canton of Geneva, Switzerland, between December 2012 and January 2013.

The context of Switzerland is indeed of particular interest. Switzerland lobbies beside the European Union in the post-Kyoto negotiations, urging for ambitious agreements. However, since its climate policy can be continuously challenged through the instruments of semi-direct democracy, the gap between government's targets and feasible policies may be very large. Following the public rejection of three energy-tax proposals in 2000, Switzerland adopted a climate strategy based on voluntary agreements and only in the late 2000s introduced a carbon tax, but covering only heating fuels (cf. Thalmann 2004; Baranzini et al. 2004) ${ }^{1}$. After that Switzerland missed its objective of $\mathrm{CO}_{2}$ emissions reduction in 2012, the carbon tax rate was revised upward, but an extension of the tax base to all fuels may be desirable to reach the more ambitious abatement targets currently under consideration .

\footnotetext{
${ }^{*}$ Corresponding author: stefano.carattini@hesge.ch. Phone: +41-22-388-18-86. A. Baranzini: andrea.baranzini@hesge.ch.

${ }^{\dagger}$ Haute école de gestion de Genève, HES-SO // University of Applied Sciences Western Switzerland, 7 route de Drize, 1227 Carouge (Geneva), Switzerland.

${ }^{\ddagger}$ Departament de Teoria Econòmica, Universitat de Barcelona, Av. Diagonal 696, 08034 Barcelona, Spain.

${ }^{1}$ The tax exists since 2008. The current tax rate is $60 \mathrm{CHF} / \mathrm{tonCO}_{2}$, but the government can increase it up to $120 \mathrm{CHF} /$ ton $\mathrm{CO}_{2}$ if deemed necessary. As of March 2014, $1 \mathrm{CHF} \approx 1.1 \mathrm{USD} \approx 0.8 \mathrm{EUR}$. Two thirds of revenues are redistributed lump-sum to households and through lower social contributions to firms. The remaining third is allocated to finance energy-efficiency investments in the building sector.
} 
Actually, the debate on Swiss energy and climate policy may reopen sooner than expected. First, semi-direct democracy allows also for bottom-up proposals. For instance, a pending popular initiative seeks the full replacement of the $8 \%$ VAT by an energy tax $^{2}$. Second, in the aftermath of Fukushima, Switzerland decided to start to phase-out nuclear energy. Currently, $40 \%$ of electricity is from nuclear sources, which implies very low carbon emissions from electricity in international comparison and little room for maneuver to replace nuclear energy without increasing carbon emissions. This is likely to imply the need for substantial reductions in consumption (Baranzini et al. 2013). Third, the Swiss government recently reported the need of additional funding for highway maintenance and thus proposed to increase fuel taxes.

Increments of energy prices are then expected from both higher taxation of fossil fuels and reforms in the electricity market. Consequences on poor and rural households represent a public concern and call for social cushioning. Carefully designing the instruments of climate policy may prove crucial in this challenging context. Indeed, revenues from a carbon tax may look as an attractive option for funding the Swiss transition towards a low-carbon economy, provided that sufficient political support is ensured.

The main aim of this paper is to determine which policy features impact acceptability. We are interested in determining whether citizens in Geneva show a positive demand for climate change mitigation, depending on socioeconomic characteristics and policy's perceptions, and what policy design may have an impact on carbon tax acceptability. Indeed, policymakers can hardly modify their population composition, but do have the ability to design effective and acceptable policies. The structure of the paper is the following. Section 2 describes the survey, sample characteristics and descriptive statistics. Econometric results are discussed in section 3, section 4 concludes.

\section{Survey design and data description}

\subsection{Qualitative survey}

To define the questions of the quantitative survey, we first administer a qualitative survey taking between 20 to 30 minutes to a small sample of 40 adults living in the Canton of Geneva. The survey is organized around 5 open questions, conceived to understand individual's perceptions and concerns regarding climate policy and carbon taxes ${ }^{3}$. Recurrent answers indicate that private actions (e.g. improvements in energy efficiency) are preferred to public intervention, the latter being barely mentioned as a possible way out to curb energy consumption and emissions. When interviewers introduce the role of the public sector, the general opinion is to limit intervention to communication and education (i.e. suasion). Market instruments are mentioned only by few, and subsidies (e.g. for public transportation) are by large preferred to taxes, in line with Cherry et al. (2012).

When asked about future energy prices, most individuals expect an upward trend. We observe that respondents are well informed about the nuclear phasing-out program as announced by the Swiss government a few months before. Social cushioning for lowincome households receives general support in the follow-up questions asking for the consequences of the expected price increases. Respondents seem however not particularly concerned by the effects on rural households, arguably because in the specific case of

\footnotetext{
${ }^{2}$ Another initiative seeks more in general to reduce Switzerland's carbon footprint through the buildup of a green economy. A third one aims at improving substantially energy efficiency and replacing energy from fossil sources with electricity. All these initiatives are likely to be submitted to the population by the end of 2015 .

${ }^{3}$ The full set of transcripts of the qualitative survey is available by the authors upon request.
} 
Geneva the countryside hosts high-income households attracted by calmness, green spaces and possibly interesting fiscal conditions.

Regarding the possible implementation of a carbon tax, respondents often state that at a first sight there are no conditions under which they would accept a generalized carbon tax, many feeling that they are already paying enough taxes. However, a followup question shows that the tax may enjoy moderate support if any potential inequality on household's income distribution would be offset. Frequent critics to the tax include distrust in the government and a presumed ineffectiveness of the carbon tax in changing behavior. We also realize that people are relatively badly informed about the existence of a tax on heating fuels.

We also ask how tax revenues should be used, for instance to finance environmental projects, social cushioning programs or refunded through tax rebates. Most respondents support the use of fiscal revenues in the environmental domain, also when the different recycling options are not explicitly mentioned. Actually, respondents are generally disconcerted about the possibility of using the revenues of an environmental tax for something unrelated to the environment. Social cushioning is also considered as important, but it seems that the way of financing it should make abstraction of environmental tax revenues. Finally, respondents would like to pay fewer income taxes, but they do not believe that the government would renounce to the opportunity of collecting new revenues (see Hahn 2009).

\subsection{Quantitative survey}

\subsubsection{Sample properties}

From December 2012 to January 2013, we surveyed through face-to-face interviews a sample of 400 adults living in the Canton of Geneva with a pre-tested questionnaire, supported by the qualitative analysis. To test for possible labeling effects, we administered two types of questionnaires: half of the sample received a questionnaire with the wording "carbon tax" (hereafter CT), while the remaining with "climate contribution" $(\mathrm{CC})^{4}$. Indeed, prospect theory shows that in presence of uncertainty individuals may want to take larger risks than what would be "rationally" justified, due to loss aversion (Kahneman and Tversky 2000). Individuals may thus prefer the status quo instead of dealing with climate change, in spite of the large risks and a positive expected value of climate change mitigation. However, if the original state of affairs is perceived as such that the current climate quality is at risk, individuals could accept the policy to avoid a loss in climate quality (see Kahneman and Tversky 2000 and Geisendorf 2013). In this sense, a good way to market carbon taxes may be to refer to a contribution for climate conservation, i.e. indicating that the climate is at risk and the planet may face a potential loss in climate quality.

Once eliminated all non-valid questionnaires, our sample is composed by 338 observations, 158 in the $\mathrm{CT}$ and 180 in the CC sub-samples. Each questionnaire possesses the same number of questions (20), with exactly the same framing, except for the substitution of the wording "carbon tax" with "climate contribution".

Concerning external validity, the composition of the sample is fairly representative of Geneva population, except for a slight under- (over-)representation of retired (young) and low-educated individuals. The survey also identifies members of environmental organizations (hereafter "green members", $14 \%$ of the sample) and political positioning (coded as left, center, right and no positioning), and investigates individual's self-reported level

\footnotetext{
${ }^{4}$ The questionnaires are available by the authors upon request.
} 
of environmental concern. It also asks whether respondents generally trust their government $(93 \%)$ and if they are aware of the existing $\mathrm{CO}_{2}$ tax on heating fuels (only 40\%). This lack of awareness concerning current taxation confirms the preliminary evidence provided by the qualitative analysis and may be explained by the limited salience of both taxation and lump-sum refund to households through reduced healthcare bills.

Based on the socioeconomic characteristics of Table 1, we compare the CT and CC sub-samples. We do not find any statistical differences in the averages of these variables, except in the case of years of education (16 with CT compared to 15.59 with CC) and the number of adults in the households (2.15 with CT and 2.44 with CC).

\subsubsection{Variables and descriptive statistics}

In what follows, we briefly outline a selection of questions and the relative descriptive statistics. Some of them are then used as variables in the econometric analysis. Table 2 reviews the first set of questions targeting energy behavior and policy in general terms.

Energy consumption The entry questions test whether respondents care of their consumption of energy, giving different options in an attempt do reduce biased answers. The majority of respondents cares of its consumption, but in a limited way. Only a fraction of the sample (20\%) considers to be very attentive. Since for most individuals saving money is the main reason to monitor energy consumption, we may conclude that current monetary incentives are too low. Indeed, only a small proportion of the sample (7\%) considers to have reduced consumption at the maximum of capacity.

Price elasticities Question 3 asks for what price variation (in percentage) respondents would need to adjust their energy consumption by 10 percent, and thus approximates price elasticity since $\epsilon \approx \frac{\Delta \% q}{\Delta \% p}$. On average, we obtain a price elasticity for gasoline of -0.51 , for electricity of -0.60 and for heating fuels of -0.59 . These values mirror relatively well the estimates for Switzerland of Baranzini and Weber (2013) for gasoline (-0.09 in the short run and -0.34 in the long run) and of Filippini (2011) for electricity (shortrun price elasticity around -0.7), despite they reflect stated preferences and require an important cognitive effort as shown by clustering around round values (cf. Figure 1) and some extreme answers, such as supposedly completely elastic or inelastic individuals Yet, estimates are very similar if we drop extreme observations or keep only car owners to compute the elasticity of gasoline. Instead, homeowners have a larger elasticity for heating fuels $(-0.94)$ than renters $(-0.49)$, which is however in line with the literature on the asymmetric information between tenants and landlords (see e.g. Gillingham et al. 2009 for a review).

Public intervention Question 6 discusses the role of the public sector to reduce energy consumption. Only a tiny fraction of individuals $(2 \%)$ contend that there is no need to reduce energy consumption at all. Similarly, only $3 \%$ believe that energy consumption does not need to be regulated. That is, the large majority expects the government to intervene to curb energy consumption. However, as for the qualitative survey, market instruments are not the favored tool. Preferences go rather to informational campaign raising awareness and to funds for public transportation ${ }^{5}$. Those answers are in line

\footnotetext{
${ }^{5}$ Thus, our survey predicted well the strong demand for public transportation revealed by the Swiss population in the ballot of February $9^{\text {th }} 2014$, when a credit of 6.4 billions to fund public transport infrastructures was accepted with $62 \%$ of yes-votes (participation at $55 \%$, given the concomitance of another vote on the freedom of movement between Switzerland and the European Union).
} 
Figure 1: Own-price energy elasticity: kernel density estimates

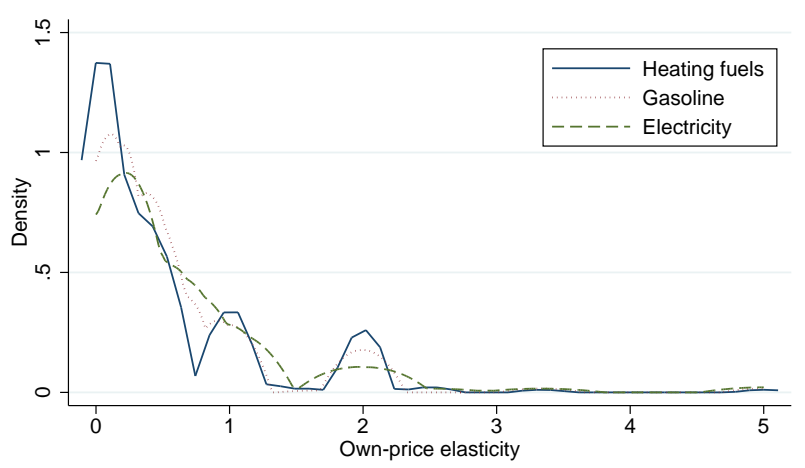

Source: Own computations. Note: Kernel density estimated with Epanechnikov kernel function with default bandwidth as for Gaussian distributions. Elasticities in absolute value.

with the increasing emphasis on integrated approaches leading to a policy-mix composed by a broader spectrum of instruments and with recent empirical evidence suggesting that subsidizing public transportation could be an effective way to reduce many road externalities (cf. e.g. Asensio et al. 2013; Lalive et al. 2013). Communication may also prove to be effective, but does not necessarily represent a substitute to taxes as suggested by economic lobbies (see Bürgenmeier et al. 2006 for the Swiss case). According to Nyborg et al. (2006), moral motivation may be positively affected by information campaigns and advertising also in presence of carbon taxes. Indeed, normative messages are expected to be effective when injunctive norms (what one should do) are aligned with descriptive norms (what others do), i.e. when influencing the perception that individuals have of the others' behavior (see below on the role of trust). In practice, policymakers can intervene e.g by improving public advertisement (see Cialdini 2003) or by rewarding those agents providing good efforts to reduce their energy consumption (Steg and Vlek 2009). For instance, in the field experiment of Schultz et al. (2007) happy smiles were pasted on the door of those households that reduced energy consumption, so to spur further cooperation. Hence, strict policy measures such as carbon taxes may perform better if coupled with a rise in awareness through effective communication (von Borgstede et al. 2013).

Yet, already at this stage $35 \%$ of respondents believe that the Swiss government should intervene with a broader carbon tax to reduce energy consumption, regardless of specific design or social cushioning. We expect this sub-sample to be more likely to support carbon taxation in the econometric analysis below.

Future energy prices In questions 7 and 8 we look at expectations about future energy prices. On average the price of gasoline is expected to increase by about $27 \%$ in the next 10 years, which may make sense in real terms assuming stricter climate policy and reasonable discounting in the oil market. However, the average is driven up by the last decile which expects price increases from $50 \%$ to $100 \%$. As commented by Alcott (2011), some consumers expect so large increases in future oil prices that it would make sense to them to trade in future markets. Scarcity is for $93 \%$ of respondents a driver of higher gasoline prices in the next 10 years. The expected price increase for heating fuels is $18 \%$ on average, with the majority of answers lying between $+10 \%$ and $+50 \%$, fairly in line with the Swiss-German survey of Alberini et al. (2013). If instead prices were to be interpreted in nominal terms (cf. Anderson et al. 2013), the expected real price increase 
would have to be corrected by expected inflation.

Interestingly, for a large majority (around 60\%) climate policy is also expected to lift prices for all energy vectors. Hence, we remark that, although the question introduces a horizon of 10 years, the field for stricter climate policy may be getting ready, in the sense that people seem to anticipate future policy tightening. However, in the meanwhile households may not only invest in energy efficiency (cf. Alberini et al. 2013) but also take advantage of current "low" prices to consume energy-intensive goods, possibly raising the issue of a demand-driven Green Paradox.

Social cushioning Question 9 focuses on the potential need for social cushioning to reduce the expected social effects of energy price increases on low-income and rural households. Not surprisingly, raising awareness $(73 \%)$ and financing public transportation (61\%) are the preferred options, in line with answers at question 6. Actually, subsidizing public transportation can be an effective way of reducing regressive effects on low-income households, since they are likely to enjoy the most a decrease in fare prices (or an increase in supply).

Regarding financial cushioning, answers are similar for subsidies and tax rebates, with a slight preference for subsidies. However, no majority is reached for any type of direct social cushioning, indicating that this may not be the priority for citizens in Geneva. Though, subsidies to low-income households receive a moderate support (38\%), whereas the very low approval for subsidies to rural regions (10\%) confirms our priors about the specific case of Geneva on this matter.

Carbon taxation We introduce the second set of questions dealing specifically with carbon taxation and apply the two labels emphasized above (cf. Table 3). In both versions of the questionnaire, we introduce the $\mathrm{CT} / \mathrm{CC}$ by saying that this potential instrument would have a tax rate of $120 \mathrm{CHF}$ per ton of $\mathrm{CO}_{2}$, implying a price increase of gasoline by about $15 \%$ and of heating fuel about $30 \%$. Despite the majority thinks that the tax would lead to a reduction in their level of energy consumption, an ample proportion of respondents (37\%) expects no change in their behavior, whereas the share of individuals pointing to an increase in consumption is non-negligible (see question 10). The latter either represent protest answer or suggest that worries of an intrinsicmotivation crowding-out may be justified.

Motivational crowding-out is indeed a hot topic in the field of environmental policy, since the work of psychologists Deci and Ryan (1985). The intuition is that economic instruments and financial compensations may turn out to have counterproductive effects on intrinsically-motivated agents. That is, ecologists that already provide large efforts for a given public good in absence of any economic incentive may feel frustrated for being taxed despite their efforts ("no behavior is good enough not to be penalized", Goeschl and Perino 2012) or less responsible toward the provision of the public good as they may think that "since I pay, I can consume and thus pollute" (Bazin et al. 2004).

Some empirical evidence underpins the existence of motivational crowding-out with external regulation (see e.g. Frey and Oberholzer-Gee 1997, Ostmann 1998 and Cardenas et al. 2000), although in the case of climate policy only the experimental evidence of Goeschl and Perino (2012) is available, with the tax reducing the willingness to buy and withdraw $\mathrm{CO}_{2}$ emissions permit from the market. Actually, according to Kirchgassner and Schneider (2003) intrinsic motivation does affect behavior, but only for low-cost decisions, while for Okey and Wright (2005), drivers enjoy anyway "negligible feelings of responsibility towards those affected by their driving" (but see also Bazin et al. 2004, 2005; Heyes and Kapur 2011). 
Interestingly, in our data we find no correlation between possible crowding-out and either the level of attention to energy consumption or the perception of being already doing a maximum of efforts (questions 1 and 2), thus supporting the interpretation of strategic answers.

Question 11 enlarges the focus and asks whether people expect the tax to be effective. A short majority (52\%) expects the tax not to be. This descriptive evidence is in line with much of the literature, which finds that in general individuals tend to neglect the incentive effect of environmental taxation (Dresner et al. 2006; Steg et al. 2006; see also Kallbekken and Aasen 2010; Sælen and Kallbekken 2011). It also shows that people expect a larger effect on themselves than on the average population, but we cannot completely rule out strategic voting. We find a positive correlation between questions 10 and 11 but not larger than 0.27 .

Co-benefits The purpose of question 12 is to test for awareness of co-benefits. To limit biased answers, respondents are asked to spontaneously mention a list of ancillary benefits coming to their minds, if any. After mentioning a benefit, people are asked whether it would be enjoyed by themselves or the society as a whole (or both). About half of the sample $(56 \%)$ see better air quality as an ancillary benefit from carbon taxes. The proportion is lower for congestion issues, health improvements and lower risk of road accidents. Age and car ownership are both positively but only marginally correlated with perceiving individual benefits from better health and lower accidents, respectively.

Question 12 thus points to a relatively low awareness of co-benefits, which may need to be targeted through improved communication, along with primary benefits. Indeed, most studies providing monetary estimates of co-benefits suggest that they are relatively conspicuous compared to mitigation costs (see Baranzini and Carattini 2013 for a review). According to Pittel and Rübbelke (2008), co-benefits may be sufficiently large to justify cooperation in international negotiations and lead to binding international agreements, of course provided that their existence (and magnitude) is recognized.

Labeling may contribute to this issue of communication. We find that the number of co-benefits acknowledged by respondents is statistically higher in the CC sample. Taken at face value, this descriptive evidence may suggest that "climate contribution" conveys a message pointing to a general environmental improvement, which seems to go beyond $\mathrm{CO}_{2}$ emissions reduction (for which we do not have any significant difference in the frequency of answers).

Disadvantages of carbon taxation The literature acknowledges a series of unwanted side effects related with carbon taxation. Mainly, it is a matter of competitiveness and distributional effects (Baranzini et al. 2000). Indeed, despite the evidence points to rather small competitiveness effects (Mathys and de Melo 2011; see also Ambec et al. 2013), the role played by the risk of geographical carbon leakage tends to be very important in the political economy of climate policy (Mathys and de Melo 2011) ${ }^{6}$.

Distributional effects also represent an important critique to carbon taxes and, without appropriate design, a potential obstacle to its political acceptability (Metcalf 2009). They regard principally low-income and rural households, which can be more impacted than others (Baranzini et al. 2000; Zhang and Baranzini 2004) ${ }^{7}$. Empirical evidence

\footnotetext{
${ }^{6}$ That is why international negotiations are often represented as a dilemma-like game. Recent contributions suggest however different game-theoretical settings for climate change negotiations, taking into account e.g. different costs of adaptation, local co-benefits (Pittel and Rübbelke 2008) and irreversibility (Pittel and Rübbelke 2010).

${ }^{7}$ Here we refer to direct distributional effects, i.e. the direct effect of higher energy prices on house-
} 
suggests that energy consumption has a positive income elasticity but between 0 and 1, making carbon and energy taxes at least slightly regressive (see e.g. Sterner 2011 on gasoline taxes). Nonetheless, policy-related environmental improvements may benefit more the poorest households living in environmentally distressed conditions. Of course, this supposes that individuals are informed about the existence (and magnitude) of local co-benefits associated with global environmental policies. Rural households are expected to incur in a larger burden given the limited possibilities of substitution between private and public transportation in the countryside. Moreover, city dwellers may enjoy larger benefits from improved environmental quality than citizens living outside the urban areas.

In general, climate policy comes at a cost for all households, abstracting so far from revenue recycling. Thus, questions 13 and 14 deal with instrument's drawbacks, paying attention to the impact on the respondent's household and on the society, respectively. We note that the most generalized fear for respondents $(67 \%)$ is to be constrained to reduce the overall level of consumption, due to higher energy prices. Only about a fifth of the sample considers that the tax would have no negative effects on its household. Interestingly, expecting lower purchasing power does not necessarily imply a loss of comfort. That is, it appears that people in the sample feel that they could live comfortably even with less purchasing power, although they may not like it. Expecting losses of purchasing power is negatively correlated with the highest income category and expecting less comfort is positively associated with the lowest income category.

Regarding employment effects, only a small minority (5\%) is concerned about the impact on her job. This makes sense since Geneva hosts mainly tertiary activities and a very few energy-intensive industries. We also note that at the time of the survey the level of unemployment in the Canton of Geneva was $5.5 \%$.

Looking at the differences in averages across the sub-samples, descriptive evidence seems suggesting that drawbacks are more easily recognized in the CT sub-sample than with the CC.

We now turn to the effects on society. In line with the literature, regressive effects seem to represents a real concern (cf. e.g. Thalmann 2004; Bristow et al. 2010; Kallbekken et al. 2011). This may create the premises for revenue recycling and social cushioning. Consistently with what presented above, we find that only a minority (25\%) cares of distributional effects on rural households. We are instead surprised to see that only relatively small proportions of respondents are concerned by employment and competitiveness effects. In particular, the number of people concerned by unemployment issues $(11 \%)$ is only slightly larger than those concerned by their own job (correlation of $0.46)$.

Acceptability Question 15 is crucial since it allows to directly test for policy acceptability, after discussing policy's advantages and disadvantages. The share of positive answers is quite high and close to majority (49\%). Actually, the approval rate in question 15 is very close to the support given to the "Energy conservation package" in the the ballot of $2000(46.6 \% \text {, cf. Thalmann 2004) })^{8}$. Comparing the two labels, we find that there is no significant difference. Hence, it seems so far that framing may matter in influencing the perception of pros and cons, but not their balance, i.e. the outcome in terms of acceptability.

hold's budget, although indirect channels make the issue much more complex (cf. Fullerton 2011). The same applies to liquidity constraints which may lead ex-ante and ex-post effects to diverge.

${ }^{8}$ Respondents were also given the "Do not know" option. However, what we want to assess is the willingness to accept such a policy and hence consider irresolute respondents as no-voters, although abstention is always an alternative in ballots. 93 individuals are concerned. 
Social cushioning Question 16 (cf. Table 4) asks what groups of population should be compensated due to the $\mathrm{CT} / \mathrm{CC}$ perceived adverse impacts. We compare it with question 9, which is similar but relative to energy price increases in general. Comparison for low-income and rural households indicates that the demand for supporting measures is larger if energy price increases result from climate policy. Respondents seem thus more sensitive to distributive impacts when they result from a public policy, rather than from "exogenous" market forces. A possible interpretation may be that the effects of the latter are perceived as temporary or less salient since gradual. For instance, salience and perceived temporariness are supposed to matter in the elasticity of gasoline in Davis and Kilian (2011), Li et al. (2012), Scott (2012) and Baranzini and Weber (2013), although contrary evidence is provided by Anderson et al. (2013).

From Table 4, we note that social cushioning is particularly warranted for low-income households ( $72 \%$ of support), but around $50 \%-60 \%$ of respondents support also compensating measures for older people and large families. Probably administratively burdensome, cushioning of these two categories is seldom considered in the literature. Instead, previous studies pay a lot of attention to firms competitiveness, which appears not to be a concern for respondents in our sample.

The proportion of people asking for compensation towards high-income households, is particularly low (18\%), as well as for rural households. Societywide refunds, i.e. the current way of refunding tax revenues from the Swiss carbon tax on heating fuels, seems not to be the preferred option for our sample, although it represents a simple and cheap (but also possibly ununderstood) way of reducing regressivity (see e.g. Metcalf 2009; cf. Pezzey and Jotzo 2013 and Bristow et al. 2010 on tax thresholds). In particular, we remark that older people are disadvantaged by the current recycling, while answers to $16 \mathrm{~g}$ would rather justify a specific aid to this sub-population.

Revenue recycling In question 17 (see Table 4), we propose three ways of revenue recycling (and give space for an eventual fourth option). Redistribution towards affected households relates to the previous discussion on distributional effects. Tax rebates would allow for a double dividend from environmental taxation, by decreasing distortionary taxes. Earmarking tax revenues for environmental purposes is a recurrent and popular option in the literature (cf. e.g. Dresner et al. 2006; Steg et al. 2006; Kallbekken and Aasen 2010; Sælen and Kallbekken 2011). No specific earmarking, i.e. funding the general budget, underlies question 15 and represents the first best from an economic perspective (Sælen and Kallbekken 2011).

Respondents are asked to rank the alternatives in decreasing order of preference. Unsurprisingly, $60 \%$ of the respondents would like to see tax revenues used to finance environmental projects. Social cushioning comes second, while tax rebates to households and firms are supported by a small minority only.

Acceptability conditional on recycling Question 18 retests the level of acceptability, but this time conditional on earmarking and revenue recycling. In particular, it asks whether the respondent would accept a $\mathrm{CT} / \mathrm{CC}$ if revenues were to be recycled according to her wish as expressed in question 17 (and detailed in question 16 in the case of social cushioning). As shown by Table 4 , yes-votes reach now $64 \%$, i.e. about $25 \%$ more than in question 15. This result does not surprise, in the light of the findings of e.g. Kallbekken et al. (2011). Comparing the two labels, we get $60 \%$ versus $67 \%$ of yes-votes in favor of the CC sub-sample. Statistical tests substantiate this difference, providing support for the inclusion of the label variable in the econometric analyses below.

This level of support may however be misleading since obtained by assuming that 
the preferred recycling options of each individual are implemented simultaneously. In the three last columns of Table 5 we thus calculate the acceptability rate assuming that only one recycling option at time is implemented.

We observe that individuals opting for recycling through green projects and renewable energy are relatively more willing to accept the carbon tax proposed by the questionnaire in question 15 (55\%), whereas those more concerned by social impacts and fiscal neutrality have a lower approval rate ( $40 \%$ and $25 \%$, respectively). When in question 18 earmarking is introduced, the approval rate climbs for all recycling options. There are again differences, depending on the recycling option, maybe because those selecting green projects are particularly concerned by the climate issue, as shown by correlations with environmental concern, whereas the remaining individuals may seek to limit policy drawbacks. Although the different ways of recycling lead to relatively close acceptance rate as found in Thalmann (2004), we observe that tax rebate to households and firms generate the largest relative increase in acceptance (from 25\% to 53\%). However, since this category is chosen by only a small number of respondents relative to the whole sample, overall yes-votes raise of only $3 \%$ (from $47 \%$ to $50 \%$ ). Redistribution towards most affected households increases acceptability in the whole sample of about $5 \%$ (from $47 \%$ to $52 \%$ ). The largest increase in overall acceptance results from using revenues for financing environmental projects and renewable energy (from $47 \%$ to $57 \%$ ).

Tax rate So far, the questionnaire refers to a $\mathrm{CT} / \mathrm{CC}$ with a tax rate of $120 \mathrm{CHF} / \mathrm{tCO}_{2}$, causing with full pass-through an increase of about $15 \%(30 \%)$ in the current price of gasoline (heating fuels). Question 19 asks what would be the highest acceptable CT/CC tax rate, in terms of energy prices increase. The aim is to measure the intensity of policy acceptance in terms of willingness-to-pay for climate change mitigation.

Figure 2 displays the distribution of answers using interval mean values, with both histograms and kernel density. The distribution is bounded by the questionnaire (at $0 \%$ and $30 \%$ ) and centered in the $5 \%-10 \%$ interval (using interval means, the average is $7 \%$ and the median $7.5 \%$ ). Neither visual inspection nor statistical tests provide signals of a significant difference between CC and CT.

Albeit a majority supports the tax in question 18, when asked about defining themselves the tax rate, respondents tend to indicate lower rates of energy price change than what proposed the survey. The two results are not necessarily in contradiction. Voters are supposed to select the closer option to their preferences. For instance, the Norwegian choice experiment of Sælen and Kallbekken (2011) shows that respondents would prefer to decrease the current level of environmental taxes, absent earmarking for environmental purposes (but see also Bristow et al. 2010). Although this explanation may not be exhaustive, it could suggest to start with a low tax rate and increase it afterward to improve acceptability (see also Godal and Holtsmark 2001) .

\section{Econometric analysis}

\subsection{Carbon tax acceptability}

In this section we analyze the determinants of carbon tax acceptability (question 15). Since the outcome variable is Bernoulli, we apply a probit estimation strategy. Model (1)

\footnotetext{
${ }^{9}$ However, if the tax path is announced in advance, the issue of a Green Paradox may be raised, for instance if the tax is introduced in a concerted move with other countries (see Baranzini and Carattini 2013 and Di Maria et al. 2013 for a discussion).
} 
Figure 2: Tax rate: distribution of answers

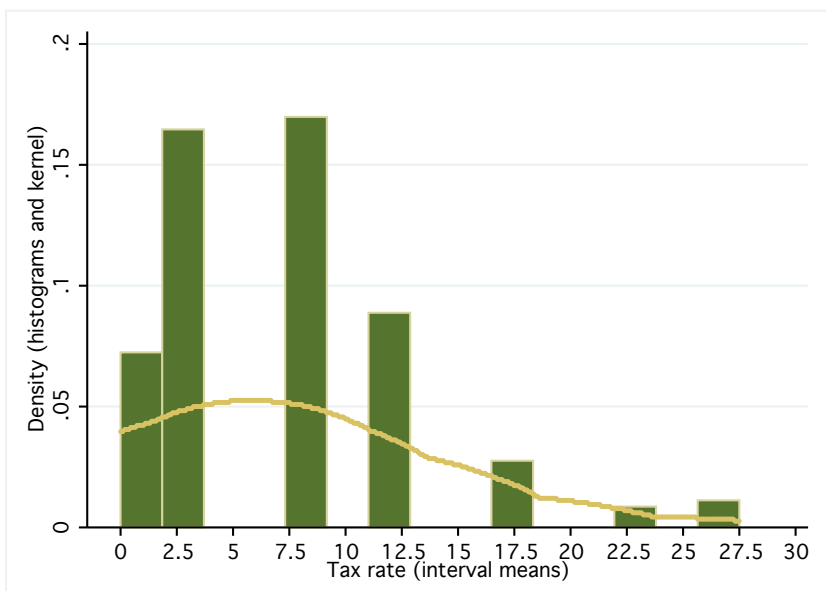

Source: Own computations. Note: Kernel density estimated with Epanechnikov kernel function and bandwidth $=5$.

estimates the effect of a vector of independent variables $x$ on the probability of accepting the carbon tax (or the climate contribution). From Greene (2011):

$$
\operatorname{Prob}(\text { Acceptability }=1 \mid x)=F(x, \beta)
$$

Equation (1) includes both continuous (e.g. number of cars) and dummy variables (e.g. green membership). In general, the marginal (or partial) effect is given by:

$$
\text { Marginal effect }=\frac{\partial F(.)}{\partial x}
$$

which is obtained by multiplying $\beta$ for the normal density. That is, $f\left(x^{\prime} \hat{\beta}\right) \hat{\beta}=\hat{f} \hat{\beta}$. For dummy variables, the change is discrete. Hence, the partial effect of a dummy $d$ is given as:

Marginal effect $=\operatorname{Prob}\left(\right.$ Acceptability $\left.=1 \mid \bar{x}_{(d)}, d=1\right)-\operatorname{Prob}\left(\right.$ Acceptability $\left.=1 \mid \bar{x}_{(d)}, d=0\right)$

where $\bar{x}_{(d)}$ is the mean of all variables but $d$. The selection of variables proceeds from the literature. Several socioeconomic factors are possible determinants of demand for environmental policy in general and climate change mitigation in particular. Among them, we obtain from our survey data on income, education, age, gender, car holding (as proxy for carbon footprint) and membership of environmental organizations (as proxy for pro-environmental behavior).

A priori, the effect of income on the acceptability of carbon taxes is ambiguous. Three main channels relate income with preferences for climate change mitigation. First, if the environment is a normal good, the higher the income, the larger the demand for environmental quality. However, the public good characteristics of climate change imply that demand for environmental quality is likely to be only partially expressed (cf. Roca 2003). Second, slight regressivity as discussed in section 2 implies that richer individuals are likely to consume less (more) energy in relative (absolute) terms and thus climate policy would impose on them a lower (larger) relative (absolute) burden. Third, environmental improvements may favor relatively more low-income households. Of course, this presumes that individuals are informed about the existence (and magnitude) of local co-benefits associated with global environmental policies.

Education is supposed to spur acceptability. Since education is a long-run investment, educated people may possess a lower discount rate than the average citizen (Bornstein and Lanz 2008). Moreover, educated people may suffer of lower informational gaps on climate change issues. Lack of information could downplay the relative benefits of climate change mitigation (cf. e.g. Cohen and Viscusi 2012$)^{10}$.

\footnotetext{
${ }^{10}$ Note however that increasing information may instead reinforce existing beliefs leading to a polarized society (Kahan et al. 2011). Individuals may also be well informed but still skeptical if they do not trust the information source, e.g. the government (Ricci et al. 2010).
} 
Age could be a determinant of political acceptability for three reasons. First, we expect the youngest generations to have larger interest for long-run environmental issues such as climate change. Second, older people may be relatively less able to adapt to higher energy prices, e.g. by substituting private with public transportation. Third, older people may also be disadvantaged by the way revenues are recycled, e.g. by lowering labor costs (Thalmann 2004).

Gender may influence acceptability as a potential determinant of differences in risk aversion and cooperative attitude, with women being perhaps more risk averse and thus less willing to be exposed to the risk of climate change (Viscusi and Zeckhauser 2006).

Car ownership is often used as a proxy for carbon footprint, although Bornstein and Lanz (2008) contend that the main transport choice for commuting may better mirror everyday carbon consumption. Carbon footprint is supposed to be negatively associated with the acceptability of carbon taxes (cf. e.g. Thalmann 2004; Kallbekken and Sælen 2011 but also Diederich and Goeschl 2013).

Ecologists are expected to be relatively more in favor of climate policy tightening, since it could provide larger effects than isolated actions (assuming no motivational crowding-out).

Since we know the postal code of each respondent, we can also distinguish individuals living in an urban environment from those residing in the countryside. Since with carbon taxes rural households are expected to incur in a relatively larger burden given the limited possibilities of substitution between private and public transportation and city dwellers are likely to enjoy larger benefits from improved environmental quality, we would expect the latter to be relatively more prone to acceptance. Yet, as said, the context of Geneva may represent a specific case in this matter.

Table 6 reports estimations results based on marginal effects at median, consistently with the median voter theorem ${ }^{11}$. The table reports a selection of variables following a stepwise procedure excluding variables associated with very large p-values. Many socioeconomic variables are thus excluded from column (1). For instance, we do not find any effect for age (both as a continuous variable or using specific groups such as e.g. youth, retired people), gender and location. The result for age is close to Bornstein and Lanz (2008) and Stadelmann-Steffen (2011) but diverges from other studies of environmental votes such as Thalmann (2004), Sciarini et al. (2007) and Bornstein and Thalmann (2008). Regarding gender, in Thalmann (2004) a significant gender gap is found only in the level of participation, whereas other ballot-based studies provide significant differences in the preferences for policy (see e.g. Sciarini et al. 2007; Bornstein and Lanz 2008; Bornstein and Thalmann 2008; Stadelmann-Steffen 2011). The effect of location is at odds with the literature on environmental ballots (e.g. Thalmann 2004; Halbheer et al. 2006; Bornstein and Thalmann 2008; Bornstein and Lanz 2008) but complies with our expectation given the particular case of Geneva. Income is also statistically non-significant and thus excluded, given also the many missing values. Although self-selection may be an issue (as remarked in section 4), the absence of an effect of income fits the theoretical prediction and is in line with the literature on environmental ballots (see e.g. Deacon and Shapiro 1975; Thalmann 2004; Bornstein and Lanz 2008). Given the descriptive statistics on price elasticity we also test the effect of home ownership and find no significant effect. Political positioning is also far from statistical significance, although its sign is positive for left-winged individuals, positive but smaller for those supporting center parties and negative for right-winged individuals (compared to no political positioning). At any rate, causality in this respect may be ambiguous (Kallbekken and Sælen 2011). As opposed to Stadelmann-Steffen (2011), we do not find any effect for being unemployed at the time of the survey. Household size does not affect acceptability either ${ }^{12}$.

Significant variables in column (1) show that the number of cars held by respondents is

\footnotetext{
${ }^{11}$ Marginal effects are derivatives computed in different ways depending on the assumed underlying distribution. Probit assumes a normal (Gaussian) distribution for F. We compare marginal effects at median with marginal effect at mean, average marginal effects, logit (which allows for "thicker tails") and OLS. Marginal effects at mean and average marginal effects are qualitatively unchanged with respect to the estimates presented in Table 7 (estimates not provided here). We find that for most coefficients the choice of the econometric model has implications for interpretation in terms of magnitude, but not of sign and significance. In the logit model co-benefits turn out to be non-significant. The same applies for OLS. The estimated model includes a heteroscedastic error term $\epsilon_{i}$. Standard errors are computed with the Delta method (cf. Greene 2011).

${ }^{12}$ All estimations are available by the authors upon request.
} 
negatively linked with the probability of accepting a carbon tax, whereas green membership and education have a positive impact. That is, as in Thalmann (2004), it is not only car ownership, but the number of vehicles that is related to political behavior. Green membership keeps its significance in all specifications, confirming the laboratory evidence of Loeschel et al. (2013). An additional year of education is linked with an increased probability of accepting the tax, mirroring the evidence on ballots (Thalmann 2004; Sciarini et al. 2007; Bornstein and Lanz 2008; Bornstein and Thalmann 2008; Stadelmann-Steffen 2011) and on the demand for climate change mitigation (see e.g. Roe et al. 2001; Achtnicht 2012; Loeschel et al. 2013).

In column (2) we apply the same stepwise procedure to the general questions on environmental attitudes. Results substantiate the relevance of the very first set of questions in the survey and provide support to internal validity. Clearly, being a priori in favor of a carbon tax has a very large effect on acceptance. Being highly concerned about climate issues and paying (no) attention to energy consumption have a significant and economically meaningful impact on acceptability, consistently with Kallbekken and Sælen (2011). Since the effect of education disappears once introduced the role of information and concern may suggest that this is rather driven by information asymmetry than a difference in discounting.

Trust in the ability of fellow-citizens to reduce energy consumption is associated with a positive effect on acceptability. Although the formulation of this variable is strictly related to energy consumption and does not recall the common wording used by large surveys such as the World Values Survey, we relate this result with the recent strand of research in the theory of collective action arguing that generalized trust may be a positive determinant of cooperative behavior in global dilemmas as with local commons (see e.g. Nyborg et al. 2006; Ostrom 2009; Carattini et al. 2013). That is, policy and individual behavior may go rather hand in hand than crowd out (Gowdy 2008; Ostrom 2009).

Trust in the ability of foreign citizens to reduce energy consumption has instead no impact on acceptability. Despite the weight given in the literature to competitiveness effects, it seems that here climate change mitigation may be rather perceived as a domestic issue. That is, conditional cooperation may be coupled with elements of Kantian responsibility, supporting the rise of unilateral policy (cf. Roemer 2010).

Unsurprisingly, trust in the government engenders higher acceptability (cf. Kirchgassner and Schneider 2003; Ostrom 2009). Government behavior represents indeed an additional source of uncertainty in the context of climate change. For instance citizens may be disappointed when looking at effective emissions reductions compared with government's rhetoric (Mitchell and Woodman 2010). Citizens may perceive environmental taxes essentially as a mean to raise additional fiscal revenues (Dresner et al. 2006; Kallbekken et al. 2011). Our result thus confirms the previous evidence of Kallbekken and Sælen (2011).

Column (3) introduces variables specifically related to carbon taxation and in particular opinions on its potential beneficialand detrimental effects. The coefficients of column (2) are generally robust to this new specification. "Government: information" now reaches significance, psuggesting the perception of a complementarity between information and taxation. According to the focus group in Kallbekken and Aasen (2010), information campaigns should accompany the implementation of climate policy providing knowledge on its instruments and not only raising awareness on climate change (see also Brannlund and Persson 2012).

The effect related with tax effectiveness, including perceived co-benefits, is striking. If the tax is expected to be effective in reducing emissions acceptability rises of about $30 \%$. The impact of co-benefits on acceptability has a similar magnitude, since this variable represents the number of co-benefits recognized by respondents and thus ranges from 0 to 8 . The estimate is also positive for expecting an effect on themselves, based on question 10. Hence, we provide strong support to the fresh literature on the perceived effectiveness of carbon taxes and its linkages with acceptability. That is, we link our finding with the emphasis on the lack of understanding of incentive effects provided by Dresner et al. (2006), with Bristow et al. (2010), which find that the acceptability of a given carbon tax design can be influenced by how agents perceive the instrument as effective, and with Brouwer et al. (2008), who point to a significant and positive effect of perceiving a hypothetical carbon travel tax as effective on travelers willingness-to-pay for carbon compensation (see also Kallbekken and Sælen 2011 on the acceptability of fuel taxes and Steg et al. 2006; Kallbekken and Aasen 2010; Sælen and Kallbekken 2011).

The coefficient for crowding-out of intrinsic motivation or protest answers does not attain 
statistical significance. This may suggest that what we face is indeed some motivational crowdingout rather than simply protest, although with no impact on acceptability.

Regarding the perceived policy drawbacks, all included variables have the expected negative sign, but only loss of purchasing power and risk of being jobless are significant. Being one of the $67 \%$ of the sample affirming that carbon taxes are an issue for purchasing power is linked with $11 \%$ lower probability of accepting the instrument. The concern of losing purchasing power makes sense in particular given that the use of tax revenues is not yet specified in the questionnaire. However, this concern may vanish over time after carbon taxes are implemented, since the real effect of loss in consumption on well-being may be lower than actually perceived, as income relative to others may be rather unchanged (Gowdy 2008, see also Howarth 2006). Not surprisingly, being in the $5 \%$ concerned about their job is associated with a $25 \%$ lower probability of acceptance.

Regressive impacts do not seem to matter, although the $p$-value is $11.5 \%$. Distributional effects are an issue for an important number of individuals as indicated in the descriptive statistics, but they fail to significantly impact policy acceptability. Our results differ thus from those of Thalmann (2004), wherein the probability of a yes-vote for a green proposal is substantially lower for those bills implying a clear increase in inequalities, of Bristow et al. (2010), whose survey data shows a marked preference for a carbon credit up to 4 tons of $\mathrm{CO}_{2}$ per capita to reduce distributional effects and of Kallbekken et al. 2011, whose laboratory evidence suggests a marked preference for fair distribution of payoffs between polluters and victims (see also Brannlund and Persson 2012). We may see an explanation in the focus group of Kallbekken and Aasen (2010), whose respondents seem to be concerned by distributional effects but not enough to pretend environmental taxes not to be regressive (cf. also Kallbekken and Sælen 2011).

Competitiveness and employment effects are clearly non-significant and thus absent from Table 7. We see three possible explanations for their non-significance. First, individuals may not care of competitiveness issues, consumers having different interests than firms, and of employment, since they may have very small empathy for potential jobless and perhaps limited fear of how rising levels of unemployment could affect their situation. This may be however in contradiction with the evidence based on voting behavior provided by Thalmann (2004), whichsuggests that almost every citizen in his sample is concerned about employment issues, even at a time when structural unemployment in Switzerland was almost nonexistent (unemployment rate was below $2 \%$ ). Second, individuals may not expect competitiveness effects to be sufficiently large to become a real concern. This may make sense in the light of the modeling exercise of Sceia et al. (2012), which find very limited terms-of-trade effects for Switzerland when simulating the impact of unilateral moves towards more stringent climate policy. Third, respondents may expect Swiss climate policy to be part of a concerted action plan undertaken with other countries, e.g. under the umbrella of a renewed Kyoto-like agreement. In such scenario, terms-of-trade effects as modeled by Sceia et al. (2012) become positive. Yet, if this is the case, we may be surprised to not find any significant effect of trust in foreign agents on acceptability. At any rate, this evidence may question the rationale for the large exemptions and privileges given to some industries by carbon schemes in some Scandinavian countries or Australia, which eventually water down the environmental impact of the tax itself (see Lin and Li 2011). The very low concern for employment and competitiveness effect may also be due to the low profile of corporate interest groups at the time of the survey. Indeed, the latter may employ massive lobbying efforts to have their vested interests internalized by the public leading so that approaching important votes the industry flight argument tend to gain a very important weight in the political discourse (Spash and Lo 2012).

Regarding the relative performance of the three specifications, we see that the goodness of fit increases as more variables are added, confirming that policy perception does matter for acceptability, beside individual characteristics. McFadden's pseudo $R^{2}$ reaches $27 \%$ in column (3) and data inspection indicates that even including all non-significant variables commented here it would not exceed $30 \%$.

\subsection{Impact of earmarking on carbon tax acceptability}

In this section, we focus on the individuals that do not accept the policy proposal in question 15 and examine whether their choice is different in question 18, conditional on the implementation 
of their preferred option of revenue recycling. The variable to be explained takes value 1 for those changing opinion in favor of the $\mathrm{CT} / \mathrm{CC}$ and 0 otherwise. We then rely again on a probit model, conditional on choosing 0 in question 15 :

$$
\operatorname{Prob}(\text { Acceptability }=1 \mid x, Q 15=0)=F(x, \beta)
$$

Revenue recycling is introduced as a dummy variable representing respondent's first choice among the three options for recycling presented in the questionnaire. We select tax rebates to households and firms as the reference case. The marginal effects are calculated as in (2) and (3).

The estimation reported in Table 7 recalls the models of Table 6 and includes variables for revenue recycling obtained from question 17 and labeling, now significant. The literature provides no priors on the potential impact of socioeconomic characteristics on acceptability conditional upon specified use of tax revenues. We find that none is statistically significant. Instead, a series of policy-relevant variables display interesting results in presence of earmarking. Trust in the government is associated with a negative sign and a fairly large coefficient. This makes sense in the light of the positive coefficient of Table 6 . Indeed, those that are in favor of the $\mathrm{CT} / \mathrm{CC}$ regardless of how tax revenues are used signal trust in the government. On the contrary, respondents distrusting the government are relatively more likely to reject the proposal of question 15 and potentially change opinion in Table 7 , once revenues are earmarked. This is consistent with the literature which points to distrust as one of the major reasons explaining the demand for earmarking, see Kallbekken and Aasen (2010) for a review.

Compared to the rest of respondents, those suggesting that the government should address the issue of energy consumption with taxation (6c) do not have a higher probability to change their opinion from question 15 to 18 . This is consistent with the effect of unconditional support to the tax as expressed in question 6 to unconditional acceptability as given by question 15 . In contrast, positive answers to 6 a (informing and raising awareness to reduce energy consumption) are again associated with an increase in acceptability. That is, those wanting the government to communicate better the need and possibilities to reduce energy consumption are, everything else equal, more likely to support the tax both unconditionally and conditionally. This may point again to the need for complementarity between taxation and communication.

The effect of perceived effectiveness is consistent with the results of Table 6. Expecting the tax to work is linked to a positive effect on acceptability, also among those that rejected the first $\mathrm{CT} / \mathrm{CC}$ proposal in question 15, arguably for other reasons. As shown by Kallbekken and Aasen (2010), being aware of how the incentive effect works does not necessarily imply no demand for earmarking. The marginal effect in Table 7 is pretty large and implies that in this sub-sample the likelihood of voting yes once the use of revenue is defined is $74 \%$ larger for those believing the $\mathrm{CT} / \mathrm{CC}$ to work than for those that do not. Albeit positive, the coefficient for co-benefits does not reach instead statistical significance.

We observe that the probability of reconsidering the $\mathrm{CT} / \mathrm{CC}$ at question 19 is larger for those selecting recycling for environmental purposes than for those opting for tax rebates, everything else equal. The coefficient for recycling through social cushioning (as defined in question 16) is not statistically significant. Therefore, it seems that earmarking for environmental purposes really matters for acceptability. Since we control for e.g. trust in the government and perceived effectiveness, we relate this demand for environmental recycling with the so-called issue-linkage, i.e. the need for the public to see a straightforward and logical nexus between the tax and the use of revenues (Sælen and Kallbekken 2011). At a given tax rate as in this context, this implies larger abatements in the way to neutrality, confirming that acceptability goes hand in hand with effectiveness (cf. Steg and Vlek 2009). We recall however that the descriptive statistics provide evidence of a positive demand for social cushioning, even though with no impact on acceptability. Therefore, policymakers may want to couple the funding of environmental projects with social cushioning, e.g. by subsidizing public transportation as with Quebec's carbon tax (Hahn 2009). Actually, this type of public intervention is strongly supported in this survey and may explain the dominance of recycling through financing for environmental purposes, since this broad concept may be seen as including public transportation. Another option would be to mix two (or more) types of revenue recycling or introduce tax thresholds (see e.g. Pezzey and Jotzo 2013), although this may be costly in terms of understanding, transparency and administrative burden. A compelling solution may rely on implementing measures of social cushioning with resources coming from the general budget and to leave tax revenues free to deliver tangible 
contribution to the environment, possibly local and visible. Measures of social cushioning may not even need to depend on climate policy, but be simply linked to energy prices, thus addressing also other issues such as the nuclear phase-out. In this sense, lump-sum transfers to households should not be excluded, provided that their progressive effect could be effectively marketed. At the end of the day these adjustments would probably not imply substantial additional burden for the government but may provide to be very effective for policy acceptability.

Finally, we look at labeling. The coefficient for CC (versus CT) is now significant. The fact that labeling affects acceptability only in conjunction with revenue recycling may hint that the term "climate contribution" may not overcome some general suspicion in question 15 , but it does increase support when earmarking is made explicit. That is, the wording "tax" seems to reduce acceptability as in Brannlund and Persson (2012, cf. also Kallbekken et al. 2011). As opined, with CC individuals may feel endowed with a state of climate which could be worsened with no contribution, consistently with Gowdy and Erickson (2005) and the seminal contributions of Thaler (1980) and Kahneman and Tversky (2000). However, chances of wording to matter may decrease in the political arena, with repeated debates and the intervention of political parties, although based on Swiss data Buetler and Maréchal (2007) call for evidence of framing effect in voting behavior.

\section{Conclusions}

Carbon taxes are an effective instrument for curbing greenhouse gas emissions, yet are seldom implemented (Baranzini and Carattini 2013). This paper analyzes drivers and barriers to public acceptability of carbon taxes. Empirical results suggest that a carbon tax could find substantial support in a ballot, but it may not reach the majority without explicit earmarking. Albeit the political discourse generally focuses on competitiveness and distributional effects (cf. e.g. Spash and Lo 2012), the data analyzed here indicate that individuals are more concerned by the effectiveness of the tax than on such drawbacks. Competitiveness effects are almost completely neglected, whereas distributional issues seem to represent a real concern, but with limited impact on acceptability. Perceived ineffectiveness represents one of the main obstacles to acceptability. According to our findings, communicating both primary and ancillary benefits of carbon taxes seems also to be essential for improving acceptability. Along with earmarking, this could provide very useful to reduce the opposition related to mistrust in the government and Ramsey-type tax aversion (see Kallbekken et al. 2011). Indeed, we find that in terms of acceptability the best way of recycling is to give the priority to environmental spending. In the same vein, we also provide evidence that using a different label, viz. "climate contribution" rather than "carbon tax", may boost acceptability under some conditions. We relate this finding with the status-quo bias largely discussed by Kahneman and Tversky (2000). We also find that trust in other people in country is associated with higher probability of acceptance, in line with the intuition of Ostrom (2009) and Carattini et al. (2013). However, it is still unclear how trust can be addressed although some research is moving in this direction (see e.g. Steg and Vlek 2009).

In sum our empirical findings seem providing evidence that with appropriate design the chances for climate policy tightening can be substantially improved. Although our data from Geneva may not ensure full countrywide representativity, our results may hint that the Swiss population may be now ready to accept ambitious energy and climate policy of the kind rejected in 2000, provided that policies are properly conceived. Transposability of survey estimates to real decisions needs however to take into account the room for hypothetical bias and variation in timing, which is linked to media coverage, lobbying and business-cycles effects.

Acknowledgments The authors would like to thank the staff and students of the Laboratory of Market Studies (LEM) at the Haute Ecole de Gestion de Genève (HEG-Genève) for their valuable support. We are also grateful to Boris Krey, Jordi Roca, Philippe Thalmann, Frédéric Varone and Frank Vöhringer for valuable comments and helpful discussion. We thank as well participants at seminars at ETH Zurich and at the Workshop on Economics of Energy Efficiency, Reus, and the $6^{\text {th }}$ Atlantic Workshop on Energy and Environmental Economics, A Toxa. We bear the sole responsibility of all remaining errors. Financial support from the Swiss Federal Office of Energy is acknowledged. 


\section{References}

Achtnicht, M. (2012). German car buyers' willingness to pay to reduce $\mathrm{CO}_{2}$ emissions. Climatic Change 113(3-4), 679-697.

Alberini, A., S. Banfi, and C. Ramseier (2013). Energy efficiency investments in the home: Swiss homeowners and expectations about future energy prices. The Energy Journal 34(1).

Alcott, H. (2011). Consumers' perceptions and misperceptions of energy costs. American Economic Review 101(3), 98-104.

Ambec, S., M. A. Cohen, S. Elgie, and P. Lanoie (2013). The Porter hypothesis at 20: Can environmental regulation enhance innovation and competitiveness? Review of Environmental Economics and Policy 7(1), 2-22.

Anderson, S. T., R. Kellogg, and J. M. Sallee (2013). What do consumers believe about future gasoline prices? Journal of Environmental Economics and Management 66(3), 383-403.

Asensio, J., A. Gómez-Lobo, and A. Matas (2013). How effective are policies to reduce gasoline consumption? Evaluating a quasi-natural experiment in Spain. Documents de treball IEB (9), $1-35$.

Baranzini, A. and S. Carattini (2013). Taxation of emissions of greenhouse gases: The environmental impacts of carbon taxes. In Global Environmental Change. Bill Freedman (Ed.), SpringerReference.

Baranzini, A., J. Goldemberg, and S. Speck (2000). A future for carbon taxes. Ecological Economics 32(3), 395-412.

Baranzini, A., P. Thalmann, and C. Gonseth (2004). Swiss climate policy: Combining VAs with other instruments under the menace of $\mathrm{a}_{2}$ tax. In Voluntary Approaches In Climate Policy. Andrea Baranzini, Philippe Thalmann (Eds.).

Baranzini, A. and S. Weber (2013). Elasticities of gasoline demand in Switzerland. Energy Policy 63, 674-680.

Baranzini, A., S. Weber, M. Bareit, and N. A. Mathys (2013). The causal relationship between energy use and economic growth in Switzerland. Energy Economics 36, 464-470.

Baumol, W. J. and W. E. Oates (1971). The use of standards and prices for protection of the environment. The Swedish Journal of Economics 73(1), 42-54.

Bazin, D., J. Ballet, and D. Touahri (2004). Environmental responsibility versus taxation. Ecological Economics 49(2), 129-134.

Bazin, D., J. Ballet, and D. Touahri (2005). Psychological effect of taxation and responsibility. A reply to Thomas A. Okey and Bruce A. Wright. Ecological Economics 53(3), 295-298.

Bornstein, N. and B. Lanz (2008). Voting on the environment: Price or ideology? Evidence from Swiss referendums. Ecological Economics 67(3), 430-440.

Bornstein, N. and P. Thalmann (2008). "I pay enough taxes already!" Applying economic voting models to environmental referendums. Social Science Quarterly 89(5), 1336-1355.

Brannlund, R. and L. Persson (2012). To tax, or not to tax: preferences for climate policy attributes. Climate Policy 12(6), 704-721.

Bürgenmeier, B., A. Baranzini, C. Ferrier, C. Germond-Duret, K. Ingold, S. Perret, P. Rafaj, S. Kypreos, and A. Wokaun (2006). Economics of climate policy and collective decision making. Climatic Change 79(1-2), 143-162. 
Bristow, A. L., M. Wardman, A. M. Zanni, and P. K. Chintakayala (2010). Public acceptability of personal carbon trading and carbon tax. Ecological Economics 69(9), 1824-1837.

Brouwer, R., L. Brander, and P. V. Beukering (2008). "A convenient truth": Air travel passengers' willingness to pay to offset their $\mathrm{CO}_{2}$ emissions. Climatic Change 90(3), 299-313.

Buetler, M. and M. A. Maréchal (2007). Framing effects in political decision making: Evidence from a natural voting experiment. CESifo Working Paper Series 1940, CESifo Group Munich.

Carattini, S., A. Baranzini, and J. Roca (2013). Unconventional determinants of greenhouse gas emissions: The role of trust. SSRN Scholarly Paper ID 2286025, Social Science Research Network.

Cardenas, J.-C., J. K. Stranlund, and C. Willis (2000). Local environmental control and institutional crowding-out. World Development 28(10), 1719-1733.

Cherry, T. L., S. Kallbekken, and S. Kroll (2012). The acceptability of efficiency-enhancing environmental taxes, subsidies and regulation: An experimental investigation. Environmental Science 83 Policy 16, 90-96.

Cialdini, R. B. (2003). Crafting normative messages to protect the environment. Current Directions in Psychological Science 12(4), 105-109.

Cohen, M. A. and W. K. Viscusi (2012). The role of information disclosure in climate mitigation policy. Climate Change Economics 03(04).

Davis, L. W. and L. Kilian (2011). Estimating the effect of a gasoline tax on carbon emissions. Journal of Applied Econometrics 26(7), 1187-1214.

Deacon, R. T. and P. Shapiro (1975). Private preference for collective goods revealed through voting on referenda. American Economic Review 65(5), 943-55.

Deci, E. L. and R. M. Ryan (1985). Intrinsic Motivation and Self-Determination in Human Behavior. Springer.

Di Maria, C., I. A. Lange, and E. v. d. Werf (2013). Going full circle: Demand-side constraints to the green paradox. CESifo Working Paper Series 4152, CESifo Group Munich.

Diederich, J. and T. Goeschl (2013). Willingness to pay for voluntary climate action and its determinants: Field-experimental evidence. Environmental and Resource Economics, 1-25.

Dresner, S., L. Dunne, P. Clinch, and C. Beuermann (2006). Social and political responses to ecological tax reform in Europe: An introduction to the special issue. Energy Policy 34(8), 895-904.

Felder, S. and R. Schleiniger (2002). Environmental tax reform: Efficiency and political feasibility. Ecological Economics 42(1-2), 107-116.

Filippini, M. (2011). Short- and long-run time-of-use price elasticities in Swiss residential electricity demand. Energy Policy 39(10), 5811-5817.

Frey, B. S. and F. Oberholzer-Gee (1997). The cost of price incentives: An empirical analysis of motivation crowding-out. American Economic Review 87(4), 746-55.

Fullerton, D. (2011). Six distributional effects of environmental policy. Working Paper 16703, National Bureau of Economic Research.

Geisendorf, S. (2013). How change happens? The status quo bias in climate policy.

Gillingham, K., R. G. Newell, and K. Palmer (2009). Energy efficiency economics and policy. Annual Review of Resource Economics 1(1), 597-620. 
Godal, O. and B. Holtsmark (2001). Greenhouse gas taxation and the distribution of costs and benefits: The case of Norway. Energy Policy 29(8), 653-662.

Goeschl, T. and G. Perino (2012). Instrument choice and motivation: Evidence from a climate change experiment. Environmental \& Resource Economics 52(2), 195-212.

Gowdy, J. and J. Erickson (2005). Ecological economics at a crossroads. Ecological Economics 53(1), 17-20.

Gowdy, J. M. (2008). Behavioral economics and climate change policy. Journal of Economic Behavior ES Organization 68(3-4), 632-644.

Greene, W. H. (2011). Econometric Analysis. Prentice Hall.

Hahn, R. W. (2009). Greenhouse gas auctions and taxes: Some political economy considerations. Review of Environmental Economics and Policy 3(2), 167-188.

Halbheer, D., S. Niggli, and A. Schmutzler (2006). What does it take to sell environmental policy? An empirical analysis of referendum data. Environmental \& Resource Economics 33(4), 441462 .

Heyes, A. G. and S. Kapur (2011). Regulating altruistic agents. Canadian Journal of Economics $44(1), 227-246$.

Howarth, R. B. (2006). Optimal environmental taxes under relative consumption effects. Ecological Economics 58(1), 209-219.

Kahan, D., M. Wittlin, E. Peters, P. Slovic, L. Ouellette, D. Braman, and G. Mandel (2011). The tragedy of the risk-perception commons: Culture conflict, rationality conflict, and climate change. SSRN Scholarly Paper ID 1871503, Social Science Research Network.

Kahneman, D. and A. Tversky (2000). Choices, Values, and Frames. Cambridge University Press.

Kallbekken, S. and M. Aasen (2010). The demand for earmarking: Results from a focus group study. Ecological Economics 69(11), 2183-2190.

Kallbekken, S., S. Kroll, and T. L. Cherry (2011). Do you not like Pigou, or do you not understand him? Tax aversion and revenue recycling in the lab. Journal of Environmental Economics and Management 62(1), 53-64.

Kallbekken, S. and H. Sælen (2011). Public acceptance for environmental taxes: Self-interest, environmental and distributional concerns. Energy Policy 39(5), 2966-2973.

Kirchgassner, G. and F. Schneider (2003). On the political economy of environmental policy. Public Choice 115(3-4), 369-96.

Lalive, R., S. Luechinger, and A. Schmutzler (2013). Does supporting passenger railways reduce road traffic externalities? ECON - Working Paper 110, Department of Economics - University of Zurich.

Li, S., J. Linn, and E. Muehlegger (2012). Gasoline taxes and consumer behavior. Working Paper 17891, National Bureau of Economic Research.

Lin, B. and X. Li (2011). The effect of carbon tax on per capita $\mathrm{CO}_{2}$ emissions. Energy Policy 39(9), 5137-5146.

Loeschel, A., B. Sturm, and C. Vogt (2013). The demand for climate protection - Empirical evidence from Germany. Economics Letters 118(3), 415-418.

Mathys, N. A. and J. de Melo (2011). Political economy aspects of climate change mitigation efforts. The World Economy 34(11), 1938-1954. 
Metcalf, G. E. (2009). Designing a carbon tax to reduce U.S. greenhouse gas emissions. Review of Environmental Economics and Policy 3(1), 63-83.

Mitchell, C. and B. Woodman (2010). Towards trust in regulation - Moving to a public value regulation. Energy Policy 38(6), 2644-2651.

Nyborg, K., R. B. Howarth, and K. A. Brekke (2006). Green consumers and public policy: On socially contingent moral motivation. Resource and Energy Economics 28(4), 351-366.

Okey, T. A. and B. A. Wright (2005). Sufficient fuel taxes would enhance ecologies, economies, and communities. Ecological Economics 53(1), 1-4.

Ostmann, A. (1998). External control may destroy the commons. Rationality and Society 10(1), $103-122$.

Ostrom, E. (2009). A polycentric approach for coping with climate change. Policy Research Working Paper Series, The World Bank.

Pezzey, J. C. V. and F. Jotzo (2013). Carbon tax needs thresholds to reach its full potential. Nature Climate Change 3(12), 1008-1011.

Pittel, K. and D. T. G. Rübbelke (2008). Climate policy and ancillary benefits: A survey and integration into the modelling of international negotiations on climate change. Ecological Economics 68(1-2), 210-220.

Pittel, K. and D. T. G. Rübbelke (2010). Transitions in the negotiations on climate change: From prisoner's dilemma to chicken and beyond. International Environmental Agreements: Politics, Law and Economics 12(1), 23-39.

Ricci, M., P. Bellaby, and R. Flynn (2010). Engaging the public on paths to sustainable energy: Who has to trust whom? Energy Policy 38(6), 2633-2640.

Roca, J. (2003). Do individual preferences explain the environmental Kuznets curve? Ecological Economics 45(1), 3-10.

Roe, B., M. F. Teisl, A. Levy, and M. Russell (2001). US consumers' willingness to pay for green electricity. Energy Policy 29(11), 917-925.

Roemer, J. E. (2010). Kantian equilibrium. Scandinavian Journal of Economics 112(1), 1-24.

Sceia, A., J.-C. Altamirano-Cabrera, M. Vielle, and N. Weidmann (2012). Assessment of acceptable Swiss post-2012 climate policies. Swiss Journal of Economics and Statistics (SJES) $148(\mathrm{II}), 347-380$.

Schultz, P. W., J. M. Nolan, R. B. Cialdini, N. J. Goldstein, and V. Griskevicius (2007). The constructive, destructive, and reconstructive power of social norms. Psychological Science 18(5), 429-434.

Sciarini, P., N. Bornstein, and B. Lanz (2007). The determinants of voting choices on environmental issues: A two-level analysis. In The dynamics of referendum campaigns. An international perspective, pp. 234-266. Claes H. de Vreese (Ed.), Palgrave Macmillan.

Scott, K. R. (2012). Rational habits in gasoline demand. Energy Economics 34(5), 1713-1723.

Sælen, H. and S. Kallbekken (2011). A choice experiment on fuel taxation and earmarking in Norway. Ecological Economics 70(11), 2181-2190.

Spash, C. L. and A. Y. Lo (2012). Australia's carbon tax: A sheep in wolf's clothing? The Economic and Labour Relations Review 23(1), 67-85.

Stadelmann-Steffen, I. (2011). Citizens as veto players: Climate change policy and the constraints of direct democracy. Environmental Politics 20(4), 485-507. 
Steg, L., L. Dreijerink, and W. Abrahamse (2006). Why are energy policies acceptable and effective? Environment and Behavior 38(1), 92-111.

Steg, L. and C. Vlek (2009). Encouraging pro-environmental behaviour: An integrative review and research agenda. Journal of Environmental Psychology 29(3), 309-317.

Sterner, T. (2007). Fuel taxes: An important instrument for climate policy. Energy Policy 35 (6), $3194-3202$.

Sterner, T. (Ed.) (2011). Fuel Taxes and the Poor: The Distributional Effects of Gasoline Taxation and Their Implications for Climate Policy. RFF Press.

Thaler, R. (1980). Toward a positive theory of consumer choice. Journal of Economic Behavior \& Organization 1(1), 39-60.

Thalmann, P. (2004). The public acceptance of green taxes: 2 million voters express their opinion. Public Choice 119, 179-217.

UNEP (2013). The emissions gap report 2013 - A UNEP synthesis report.

Viscusi, W. K. and R. J. Zeckhauser (2006). The perception and valuation of the risks of climate change: A rational and behavioral blend. Climatic Change 77(1-2), 151-177.

von Borgstede, C., M. Andersson, and F. Johnsson (2013). Public attitudes to climate change and carbon mitigation - Implications for energy-associated behaviours. Energy Policy 57, $182-193$.

Zhang, Z. X. and A. Baranzini (2004). What do we know about carbon taxes? An inquiry into their impacts on competitiveness and distribution of income. Energy Policy 32(4), 507-518. 


\section{Tables}

Table 1: Socioeconomic characteristics: sample's summary statistics

\begin{tabular}{lccccc}
\hline \multicolumn{1}{c}{ Variable } & Mean & (Std. Dec.) & Min. & Max. & N \\
\hline Gender (male) & 0.521 & $(0.5)$ & 0 & 1 & 336 \\
Age & 36.860 & $(14.04)$ & 19 & 85 & 336 \\
Years of education & 15.782 & $(1.935)$ & 11 & 18 & 330 \\
Categories of income & 4.029 & $(1.816)$ & 1 & 7 & 239 \\
Labor market (active) & 0.949 & $(0.221)$ & 0 & 1 & 332 \\
Number of adults in the household & 2.306 & $(1.194)$ & 0 & 6 & 337 \\
Number of kids in the household & 0.333 & $(0.681)$ & 0 & 4 & 291 \\
Homeowner & 0.223 & $(0.417)$ & 0 & 1 & 336 \\
Number of cars & 1.279 & $(0.957)$ & 0 & 4 & 337 \\
& Source: Own computations. & & &
\end{tabular}


Table 2: Questions and answers: energy consumption

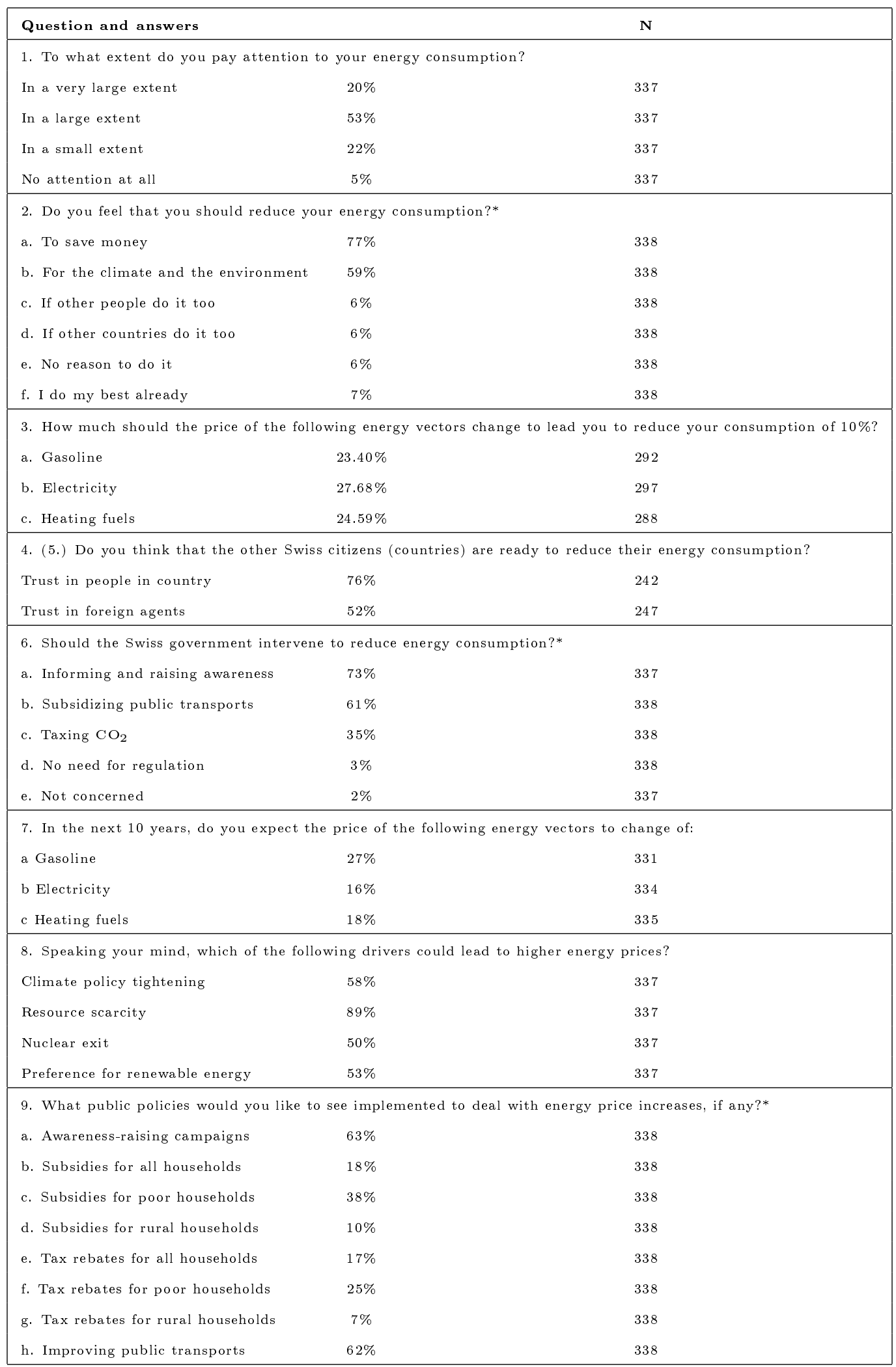

Source: Own computations. Note: Questions 1 to 9. Questions 10 to 19 below. ${ }^{*}$ Multiple answers are possible. 
Table 3: Questions and answers: carbon tax and climate contribution

\begin{tabular}{|c|c|c|c|c|}
\hline \multicolumn{4}{|c|}{ Question and answers } & $\mathbf{N}$ \\
\hline \multicolumn{5}{|c|}{ 10. Do you think that a CT/CC would affect your energy consumption? } \\
\hline \multicolumn{2}{|c|}{ Less consumption } & \multicolumn{2}{|l|}{$56 \%$} & 338 \\
\hline No change & \multicolumn{3}{|c|}{$37 \%$} & 338 \\
\hline More consumption & \multicolumn{3}{|c|}{$7 \%$} & 338 \\
\hline \multicolumn{5}{|c|}{ 11. Do you think that a CT/CC could achieve energy consumption reductions for Switzerland? } \\
\hline The tax is effective & \multicolumn{3}{|c|}{$48 \%$} & 338 \\
\hline \multicolumn{5}{|c|}{ 12. What are the advantages of a $\mathrm{CT} / \mathrm{CC}$ that come to your mind? } \\
\hline & For the respondent only & Only for the society & For both & \\
\hline a. Better air quality & $10 \%$ & $26 \%$ & $20 \%$ & 320 \\
\hline b. Less congestion & $7 \%$ & $14 \%$ & $6 \%$ & 320 \\
\hline c. Health improvement & $16 \%$ & $11 \%$ & $15 \%$ & 320 \\
\hline d. Less road accidents & $5 \%$ & $10 \%$ & $3 \%$ & 320 \\
\hline \multicolumn{5}{|c|}{ 13. What drawbacks do you see for your household linked with a CT/CC?* } \\
\hline a. Less purchasing power & & \multicolumn{2}{|l|}{$67 \%$} & 338 \\
\hline b. Less comfort & & \multicolumn{2}{|l|}{$34 \%$} & 338 \\
\hline c. Fear of losing the job & & \multicolumn{2}{|l|}{$5 \%$} & 338 \\
\hline d. No drawbacks & & \multicolumn{2}{|l|}{$22 \%$} & 338 \\
\hline \multicolumn{5}{|c|}{ 14. What drawbacks do you see for the Swiss society linked with a CT/CC?* } \\
\hline a. Less purchasing power & & \multicolumn{2}{|l|}{$69 \%$} & 338 \\
\hline b. Loss of competitiveness & & \multicolumn{2}{|l|}{$20 \%$} & 338 \\
\hline c. Distributional effects on the poor & & \multicolumn{2}{|l|}{$46 \%$} & 338 \\
\hline d. Rise in unemployment & & \multicolumn{2}{|l|}{$11 \%$} & 338 \\
\hline e. Inequality city-countryside & & \multicolumn{2}{|l|}{$25 \%$} & 338 \\
\hline f. No drawbacks & & \multicolumn{2}{|l|}{$11 \%$} & 338 \\
\hline \multicolumn{5}{|c|}{ 15. Despite these drawbacks (from questions 13 and 14 ), would you accept a CT/CC ? } \\
\hline Acceptability despite drawbacks & & $49 \%$ & & 338 \\
\hline
\end{tabular}

Source: Own computations. Note: See Table 5 for question 15 onward. *Multiple answers are possible. 
Table 4: Questions and answers: policy design (carbon tax/climate contribution)

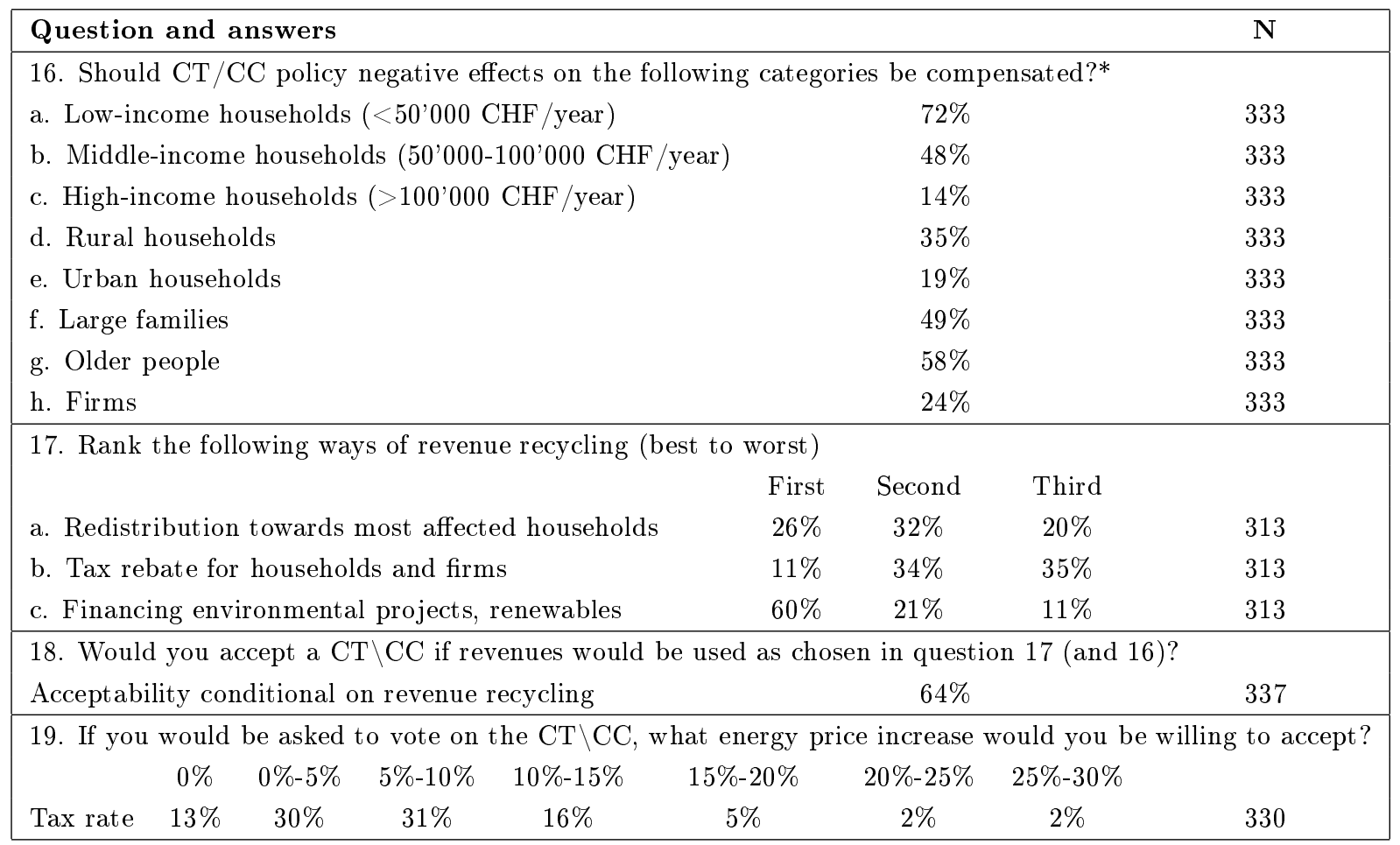

Source: Own computations. Note: ${ }^{*}$ Multiple answers are possible. 


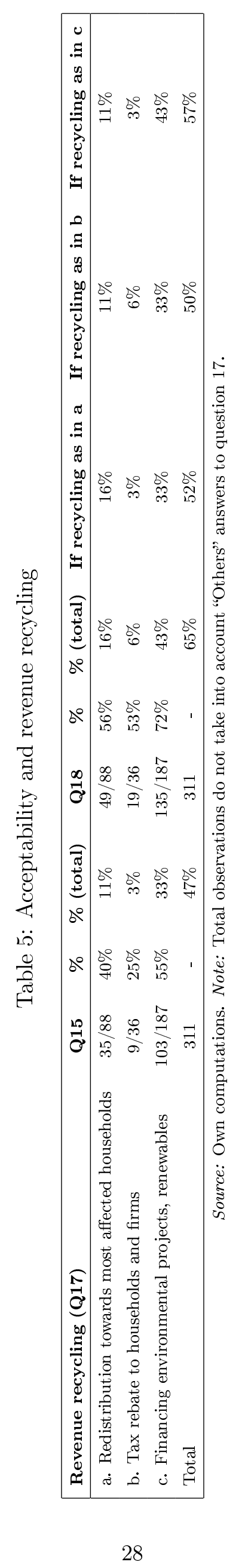


Table 6: Testing carbon tax/climate contribution acceptability: marginal effects at median from probit estimation

\begin{tabular}{|c|c|c|c|}
\hline Question 15 & $(1)$ & $(2)$ & $(3)$ \\
\hline Number of cars & $\begin{array}{c}-0.073^{* *} \\
(0.029)\end{array}$ & $\begin{array}{l}-0.053^{*} \\
(0.032)\end{array}$ & $\begin{array}{l}-0.061^{*} \\
(0.033)\end{array}$ \\
\hline Green member & $\begin{array}{c}0.275^{* * *} \\
(0.074)\end{array}$ & $\begin{array}{c}0.205^{* *} \\
(0.094)\end{array}$ & $\begin{array}{c}0.191^{* *} \\
(0.094)\end{array}$ \\
\hline Years of education & $\begin{array}{c}0.028^{* *} \\
(0.015)\end{array}$ & $\begin{array}{c}0.014 \\
(0.016)\end{array}$ & $\begin{array}{c}0.012 \\
(0.017)\end{array}$ \\
\hline Climate: high concern & & $\begin{array}{c}0.161^{* * *} \\
(0.061)\end{array}$ & $\begin{array}{c}0.136^{* *} \\
(0.067)\end{array}$ \\
\hline Energy consumption: no attention & & $\begin{array}{c}-0.334^{* * *} \\
(0.126)\end{array}$ & $\begin{array}{c}-0.375^{* * *} \\
(0.100)\end{array}$ \\
\hline Trust in other people in country & & $\begin{array}{c}0.107^{*} \\
(0.062)\end{array}$ & $\begin{array}{c}0.077 \\
(0.066)\end{array}$ \\
\hline Trust in the government & & $\begin{array}{l}0.210^{*} \\
(0.111)\end{array}$ & $\begin{array}{c}0.118 \\
(0.134)\end{array}$ \\
\hline Government intervention: information & & $\begin{array}{c}0.094 \\
(0.070)\end{array}$ & $\begin{array}{l}0.124^{*} \\
(0.071)\end{array}$ \\
\hline Government intervention: taxation & & $\begin{array}{c}0.269^{* * *} \\
(0.062)\end{array}$ & $\begin{array}{c}0.222^{* * *} \\
(0.069)\end{array}$ \\
\hline $\mathrm{CT} / \mathrm{CC}$ : effect on own behavior & & & $\begin{array}{c}0.174^{* *} \\
(0.072)\end{array}$ \\
\hline $\mathrm{CT} / \mathrm{CC}$ : crowding-out or protest answers & & & $\begin{array}{c}-0.053 \\
(0.124)\end{array}$ \\
\hline CT/CC: effectiveness & & & $\begin{array}{c}0.284^{* * *} \\
(0.068)\end{array}$ \\
\hline $\mathrm{CT} / \mathrm{CC}:$ co-benefits & & & $\begin{array}{l}0.028^{*} \\
(0.017)\end{array}$ \\
\hline $\mathrm{CT} / \mathrm{CC}$ : drawbacks (less purchasing power) & & & $\begin{array}{c}-0.165^{* *} \\
(0.076)\end{array}$ \\
\hline $\mathrm{CT} / \mathrm{CC}$ : drawbacks (fear of losing job) & & & $\begin{array}{l}-0.258^{*} \\
(0.142)\end{array}$ \\
\hline $\mathrm{CT} / \mathrm{CC}$ : drawbacks (distributional effects on the poor) & & & $\begin{array}{l}-0.104 \\
(0.065)\end{array}$ \\
\hline Pseudo $R^{2}$ & 0.05 & 0.17 & 0.27 \\
\hline Log pseudolikelihood & -214.504 & -185.982 & -163.533 \\
\hline$N$ & 327 & 325 & 325 \\
\hline
\end{tabular}

Note: Robust standard errors in parentheses. ${ }^{*} p<0.1,{ }^{* *} p<0.05,{ }^{* * *} p<0.01$. In all columns $p>C h i^{2}=$ 0.0000 . 
Table 7: Carbon tax/climate contribution acceptability with earmarking and revenue recycling: marginal effects at median from probit estimation

\begin{tabular}{lc}
\hline Question $18 \mid$ Question $15=0$ & $(1)$ \\
\hline Trust in the government & $-0.314^{*}$ \\
& $(0.155)$ \\
Government intervention: information & $0.184^{* *}$ \\
& $(0.088)$ \\
Government intervention: taxation & 0.184 \\
& $(0.088)$ \\
CT/CC: effectiveness & $0.273^{* * *}$ \\
& $(0.092)$ \\
CT/CC: co-benefits & 0.040 \\
& $(0.027)$ \\
CT/CC: drawbacks (less purchasing power) & 0.105 \\
& $(0.096)$ \\
CT/CC: drawbacks (fear of losing job) & $-0.252^{* * *}$ \\
& $(0.095)$ \\
CT/CC: drawbacks (distributional effects on the poor) & 0.022 \\
& $(0.092)$ \\
Revenue recycling: social cushioning & 0.067 \\
& $(0.123)$ \\
Revenue recycling: environmental projects & $0.205^{*}$ \\
& $(0.123)$ \\
Labeling (climate contribution) & $0.185^{* *}$ \\
& $(0.091)$ \\
\hline Pseudo $R^{2}$ & 0.18 \\
Log pseudolikelihood & -85.340 \\
& 152 \\
\hline
\end{tabular}

Note: Coefficients and goodness of fit are computed with the inclusion of the following socioeconomic variables: gender, age, education (years of), green member, number of cars, homeowner, unemployed. None of them is statistically significant. Robust standard errors in parentheses. ${ }^{*} p<0.1,{ }^{* *} p<0.05,{ }^{* * *} p<0.01$.

$$
p>C h i^{2}=0.0020 \text {. }
$$


Cahiers de recherche du Centre de Recherche Appliquée en Gestion (CRAG) de la Haute Ecole de Gestion - Genève

\section{(C) 2014}

CRAG - Centre de Recherche Appliquée en Gestion

Haute école de gestion - Genève

Campus de Battelle, Bâtiment $F$

7, route de Drize - 1227 Carouge - Suisse

$\triangle$ crag@hesge.ch

www.hesge.ch/heg/crag

(ग) +41223881818

圆 +41223881740

Tous les cahiers de recherche de la HEG sur RERO DOC : http://doc.rero.ch/collection/HEGGE i.REPORT?In=fr 